\title{
Results from the validation campaign of the ozone radiometer GROMOS-C at the NDACC station of Réunion island
}

\author{
Susana Fernandez ${ }^{1}$, Rolf Rüfenacht ${ }^{1}{ }^{\text {a }}$, Niklaus Kämpfer ${ }^{1}$, Thierry Portafaix ${ }^{2}$, Françoise Posny ${ }^{2}$, and \\ Guillaume Payen ${ }^{3}$ \\ ${ }^{1}$ Institute of Applied Physics, University of Bern, Bern, Switzerland \\ ${ }^{2}$ LACy, Université de la Réunion, Saint Denis, France \\ ${ }^{3}$ OSU-Réunion, Université de la Réunion, Saint Denis, France \\ ${ }^{a}$ now at: Leibniz-Institute of Atmospheric Physics, Kühlungsborn, Germany
}

Correspondence to: Susana Fernandez (susana.fernandez@iap.unibe.ch)

Received: 4 February 2016 - Published in Atmos. Chem. Phys. Discuss.: 11 March 2016

Revised: 9 May 2016 - Accepted: 30 May 2016 - Published: 20 June 2016

\begin{abstract}
Ozone performs a key role in the middle atmosphere and its monitoring is thus necessary.

At the Institute of Applied Physics of the University of Bern, Switzerland, we built a new ground-based microwave radiometer, GROMOS-C (GRound based Ozone MOnitoring System for Campaigns). It has a compact design and can be operated remotely with very little maintenance requirements, being therefore suitable for remote deployments. It has been conceived to measure the vertical distribution of ozone in the middle atmosphere, by observing pressure-broadened emission spectra at a frequency of $110.836 \mathrm{GHz}$. In addition, meridional and zonal wind profiles can be retrieved, based on the Doppler shift of the ozone line measured in the four directions of observation (north, east, south and west).

In June 2014 the radiometer was installed at the Maïdo observatory, on Réunion island $\left(21.2^{\circ} \mathrm{S}, 55.5^{\circ} \mathrm{E}\right)$. Highresolution ozone spectra were recorded continuously over 7 months. Vertical profiles of ozone have been retrieved through an optimal estimation inversion process, using the Atmospheric Radiative Transfer Simulator ARTS2 as the forward model. The validation is performed against ozone profiles from the Microwave Limb Sounder (MLS) on the Aura satellite, the ozone lidar located at the observatory and with ozone profiles from weekly radiosondes. Zonal and meridional winds retrieved from GROMOS-C data are validated against another wind radiometer located in situ, WIRA. In addition, we compare both ozone and winds with ECMWF (European Centre for Medium-Range Weather Forecasts) model data. Results show that GROMOS-C provides reli-
\end{abstract}

able ozone profiles between 30 and $0.02 \mathrm{hPa}$. The comparison with lidar profiles shows a very good agreement at all levels. The accordance with the MLS data set is within $5 \%$ for pressure levels between 25 and $0.2 \mathrm{hPa}$. GROMOS-C's wind profiles are in good agreement with the observations by WIRA and with the model data, differences are below $5 \mathrm{~m} \mathrm{~s}^{-1}$ for both.

\section{Introduction}

The stratospheric ozone layer absorbs ultraviolet radiation from the sun, protecting life at the surface of the Earth and, through heating by the absorbed radiation, determines the thermal state of the middle atmosphere. Variations in its concentration can significantly alter the radiative balance of the middle atmosphere and consequently influence climate through resulting circulation changes. Besides, it is well known that the ozone abundance is linked to climate change through the stratospheric cooling consequence of the greenhouse effect. The monitoring of ozone is necessary and interesting by itself, but additionally because it can be used as a tracer to study atmospheric dynamics processes (Brasseur and Solomon, 2005; Flury et al., 2009; Scheiben et al., 2012). Ozone spectra can further be used to retrieve middle atmospheric horizontal wind from the Doppler shift between the spectra measured from opposite azimuthal directions (Rüfenacht et al., 2014). Wind information is crucial to study dynamical processes in the atmosphere. However the measure- 
ment of wind between 30 and $70 \mathrm{~km}$ remains a difficult challenge.

Nowadays there is a wide variety of approaches to measure ozone profiles, from in situ aircraft and radiosondes, to remote-sensing techniques, both satellite-borne and groundbased active and passive instruments. Among all the methods, ground-based microwave radiometry is the only one that provides high temporal resolution ozone profiles up to the mesopause, continuously during both daytime and nighttime and under most weather conditions. It is a passive technique based on the observation of the radiation emitted by rotational transitions of the ozone molecules. Ground-based ozone radiometer sites in the world are scarce. Most are part of the NDACC (Network for the Detection of Atmospheric Composition Change) with permanent instruments located at meteorological observatories in Spitsbergen, Switzerland, Hawaii, New Zealand and Japan. However, many regions are not covered by this network. Continuous ozone time series measurements are needed in these regions, particularly in the Southern Hemisphere.

The Institute of Applied Physics (IAP) of the University of Bern has developed in recent years a new generation of transportable radiometers to be used in measurement campaigns. GROMOS-C is one of three mobile instruments built by the IAP, along with the wind radiometer WIRA (WInd RAdiometer, Rüfenacht et al., 2012) and the water vapour radiometer MIAWARA-C (MIddle Atmospheric WAter vapour RAdiometer for Campaigns, Straub et al., 2010). These three instruments recorded measurements together in a campaign at the Maïdo observatory (see Fig. 1). The Maïdo observatory is located on Réunion island, in the Indian ocean, at an altitude of $2200 \mathrm{~m}$ a.s.l. It was inaugurated in 2012 and hosts various instruments for atmospheric measurements, including wind and ozone lidars (Baray et al., 2013). Ozone sondes are deployed by Météo-France from a station nearby, SaintDenis, at sea level. Réunion is an important measurement site as it provides a multi-instrumented station in the Southern Hemisphere tropics.

The tropical region historically suffers from a lack of ground-based ozone measurements with high vertical and temporal resolution. Recent work has shown a significant negative ozone trend in the tropical stratosphere (Randel and Thompson, 2011), based on satellite observations combined with ozonesondes, which is likely related to modifications in the Brewer-Dobson circulation (Butchart et al., 2006). Diurnal variations of stratospheric ozone in the tropics have recently been studied by ground-based microwave radiometry at the Mauna Loa Observatory in Hawaii (Parrish et al., 2014).

With the data collected during this campaign we have been able to validate GROMOS-C performance as ozone profiler by comparing to ozone lidar, radiosondes, satellite and model data, and as a wind profiler by comparison to the wind radiometer WIRA and to model data. The goal of this manuscript is to present this validation. The paper is organ-

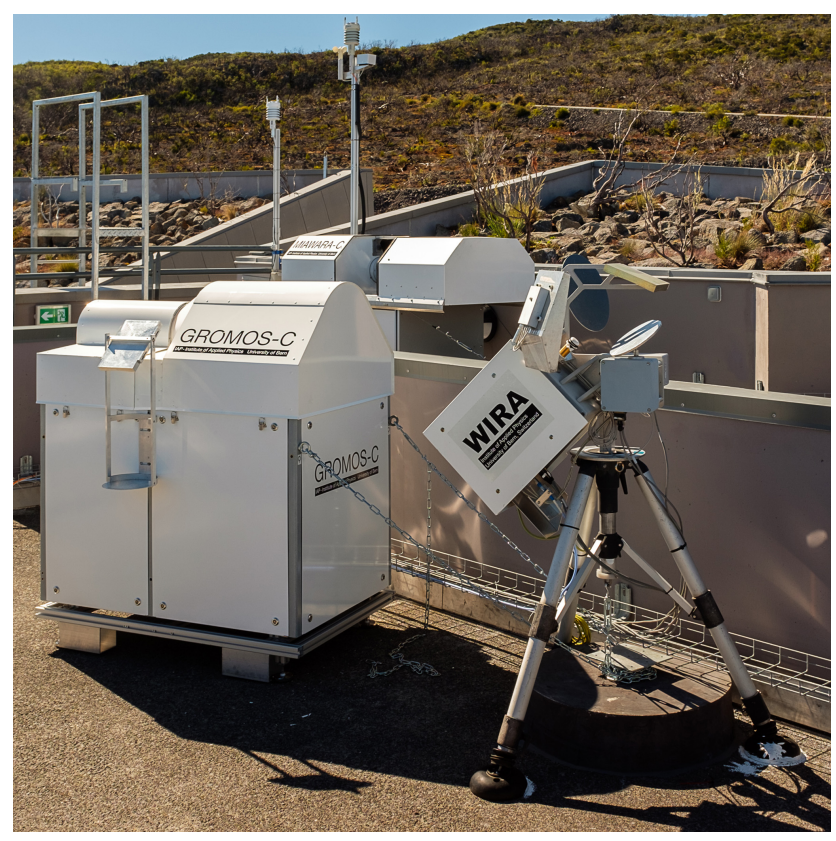

Figure 1. The ozone radiometer GROMOS-C at the Maïdo observatory, on Réunion island, together with the wind radiometer WIRA and the water vapour radiometer MIAWARA-C.

ised as follows: Sect. 2 provides a brief description of the microwave radiometer and the retrieval technique used. Section 3 presents the measurement campaign at the Maïdo observatory, including the different reference instruments. The main results of the campaign are presented in Sects. 4, 5 and 6 , including the validation of ozone and wind profiles. Finally, Sect. 7 concludes this paper.

\section{GROMOS-C}

GROMOS-C is a ground-based compact radiometer that measures the spectral intensity of the pressure-broadened rotational emission line of ozone at $110.836 \mathrm{GHz}$. A detailed description of the instrument and of the ozone profiles retrieval method can be found in Fernandez et al. (2015). The main characteristics of GROMOS-C are summarized in Table 1 .

The purpose of a microwave radiometer is to spectrally resolve the sky brightness temperature. The receiver of GROMOS-C has a noise temperature of $1080 \mathrm{~K}$ and offers the possibility to observe different emission lines: $\mathrm{O}_{3}$ at 109.559 and $110.836 \mathrm{GHz}$, and $\mathrm{CO}$ at $115.271 \mathrm{GHz}$. The signal is spectrally analysed by a fast Fourier transform spectrometer (FFTS), with a bandwidth of $1 \mathrm{GHz}$ and a resolution of $30.5 \mathrm{kHz}$. One of GROMOS-C main features is the existence of multiple calibration methods, which allows to choose the most convenient to use under different conditions (Fernandez et al., 2015, Sect. 2.3). The whole instrument is placed inside a sealed thermally insulated aluminum hous- 
Table 1. GROMOS-C main features.

\begin{tabular}{ll}
\hline Receiver type & $\begin{array}{l}\text { Preamplified heterodyne re- } \\
\text { ceiver } \\
\text { Single side band }\end{array}$ \\
Operation mode & $1080 \mathrm{~K}$ \\
Receiver noise temperature & $109-118 \mathrm{GHz}$ (tunable) \\
Frequency range & FFTS, $1 \mathrm{GHz}$ bandwidth \\
Backend & $30.5 \mathrm{kHz}$ \\
Spectral resolution & hot/cold + noise \\
Calibration & diode + tipping curve \\
& $23-70 \mathrm{~km}$ \\
\hline
\end{tabular}

ing. A window with very low losses for microwave radiation has been built above the optics. It is made of $1 \mathrm{~mm}$ thick teflon and has a shape of a section of a cone. In order to operate GROMOS-C we just have to connect it to power and the internet. It is then remotely controlled with very little maintenance requirements.

The vertical distribution of ozone is retrieved from the pressure dependence of the line width of the observed spectrum. The upper limit for the retrieval from the $110.836 \mathrm{GHz}$ line is circa $70 \mathrm{~km}$ and our lower boundary is about $23 \mathrm{~km}$ (Fernandez et al., 2015, Sect. 3.1). For the retrievals of GROMOS-C we use the Atmospheric Radiative Transfer Simulator ARTS2 (Eriksson et al., 2011) together with Qpack2 (Eriksson et al., 2005). The estimate of the ozone profile is done by means of the optimal estimation method (OEM) (Rodgers, 1976).

\section{The campaign}

Réunion island is an overseas department of France located in the Indian ocean $\left(21.2^{\circ} \mathrm{S}, 55.5^{\circ} \mathrm{E}\right)$. The Maïdo observatory was built on top of one of the highest mountains of the island, the Maïdo mountain, at $2200 \mathrm{~m}$ a.s.l. It houses a large variety of atmospheric instruments, including lidars, radiometers and in situ gas and aerosol sensors. This site is important and rare because it is a multi-instrumented meteorological station in the Southern Hemisphere tropics. Moreover, its high elevation above sea level constitutes an advantage for lidars and microwave radiometers as they benefit from the drier atmosphere which ensures lower tropospheric attenuation.

GROMOS-C was installed on the terrace of the Maïdo observatory in June 2014, and remained until the end of January 2015. High temporal resolution ozone spectra were recorded continuously for 7 months. The main goal of this measurement campaign was to validate the performance of GROMOS-C as an ozone and wind profiler by comparing to profiles from other reliable sources. Further, the highresolution ozone spectra constitute a valuable data set not previously available for this location. These data can be used to study the diurnal cycle of ozone in the tropics (Studer
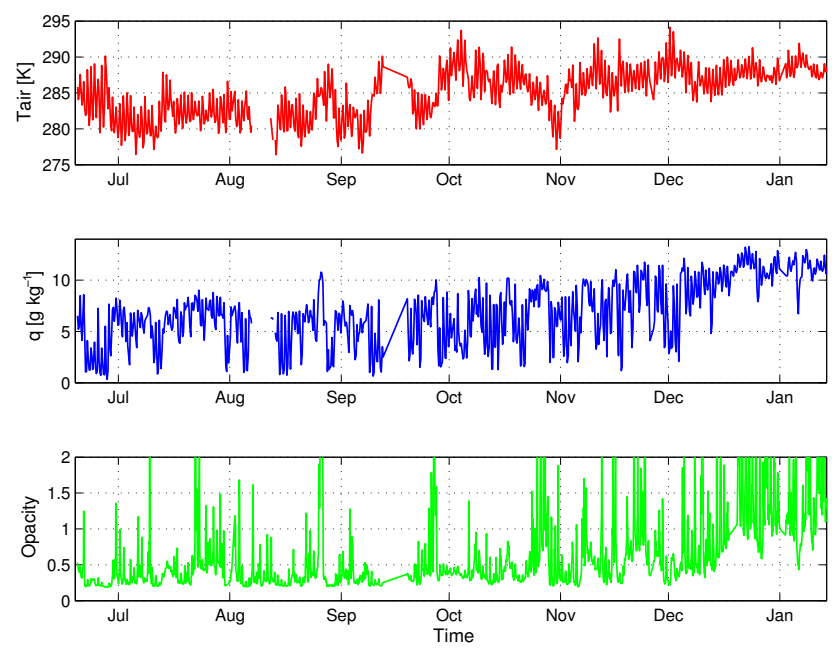

Figure 2. Air temperature (top), specific humidity (middle) and total optical thickness of the atmosphere at $22^{\circ}$ elevation at $110 \mathrm{GHz}$ (bottom), during the whole campaign at the Maïdo observatory.

et al., 2014). An accurate knowledge of diurnal ozone variation is needed for reliable trend detection in the global ozone distribution. Merging ozone data from different satellites without properly accounting for the diurnal ozone cycle would result in a systematic bias in the calculated ozone trend.

Our campaign instruments WIRA and MIAWARA-C were also involved in the campaign with measurements starting in September 2013.

Figure 2 (top panel) shows the air temperature measured by the meteorological station of GROMOS-C. We can see that during the campaign, from June to January, the weather was quite stable with minimum temperatures of $6^{\circ} \mathrm{C}$ and maximum close to $20^{\circ} \mathrm{C}$. The specific humidity is shown in the middle plot of Fig. 2. It has been calculated from the relative humidity and temperature measured by the meteorological station, and gives an idea of the increase on the amount of water in the troposphere during the summer. Atmospheric opacity was calculated periodically with the tipping curves (Fernandez et al., 2015, Sect. 2.3.3), and was found to be between 0.1 and 1 except for very humid days, which occur mainly towards the summer (December-January). An opacity value lower than 0.5 is considered to be very good. Spikes in the opacity plot correspond to clouds passing by.

The operation cycle of GROMOS-C includes four directions of sky view, north, east, south and est. All sky measurements are performed at an elevation angle of $22^{\circ}$. Afterwards the rotating mirror points to the Peltier and hot loads for calibration. The noise diode is turned on when the optics are pointing to the Peltier target. The integration time for each measurement is $1 \mathrm{~s}$. Tipping curves are performed every $15 \mathrm{~min}$. 


\subsection{Reference instruments}

\subsubsection{Aura-MLS}

The Earth Observing System Microwave Limb Sounder, EOS MLS, is a millimetre wave radiometer onboard the Aura satellite, which was launched in July 2004. Aura-MLS covers latitudes between $82^{\circ} \mathrm{S}$ and $82^{\circ} \mathrm{N}$. It is in a Sun-synchronous near-polar orbit at an altitude of $705 \mathrm{~km}$, with two overpasses per day near Réunion island. MLS observes emitted microwave radiation in limb geometry from the ground up to $96 \mathrm{~km}$. Atmospheric limb scans and radiometric calibration are performed routinely every $25 \mathrm{~s}$. Vertical profiles are retrieved every $165 \mathrm{~km}$ along the suborbital track. A detailed description of Aura-MLS can be found in Waters et al. (2006).

Ozone is observed at $240 \mathrm{GHz}$. The retrieved profiles of version v3.3 are used for this comparison. The altitude range covered goes from the upper troposphere, $260 \mathrm{hPa}$, to the mesosphere, $0.02 \mathrm{hPa}$. The vertical resolution is $3 \mathrm{~km}$ at $260 \mathrm{hPa}$, increasing to $5.5 \mathrm{~km}$ at $0.02 \mathrm{hPa}$, and the horizontal resolution goes from 300 to $500 \mathrm{~km}$, depending on the pressure level (Froidevaux et al., 2008).

\subsubsection{DIAL lidar}

A differential absorption ozone lidar (DIAL) was installed at the Maïdo observatory in 2013. It requires the use of two different emitted wavelengths. The laser sources are a tripled Nd:Yag laser, which provides the non-absorbed beam at $355 \mathrm{~nm}$, and a $\mathrm{XeCl}$ excimer laser, which provides the absorbed beam at $308 \mathrm{~nm}$. The receiving telescope is composed of four parabolic mirrors. The backscattered signal is collected by four optical fibers located at the focal point of each mirror. A Jobin Yvon holographic grating is used in the spectrometer.

The lidar provides ozone profiles over $15-45 \mathrm{~km}$ altitude. The lidar signals are recorded every $3 \mathrm{~min}$ but averaged over the whole night to increase the signal-to-noise ratio. It is necessary to apply a number of corrections to the signal. The background signal is estimated and removed using a linear regression in the high-altitude range where the useful lidar signal is negligible (over $80 \mathrm{~km}$ ). Ozone number density is retrieved from the slope of the signals after derivation (Godin-Beekmann et al., 2003). Lidar signals are corrected for the Rayleigh extinction using a pressure temperature profile from nearby radiosondes and a meteorological model.

\subsubsection{Ozone radiosondes}

Ozone soundings are performed weekly since 1998, launched from Gillot, the Météo-France station near the airport of Réunion island, at $8 \mathrm{~m}$ a.s.l. A profile is obtained up to the altitude where the balloon bursts at approximately $30 \mathrm{~km}$. Ozone is measured with an electrochemical concentration cell (ECC) (Stübi et al., 2008). The ozonesonde currently used is a ECC
Z Ensci type with a $0.5 \% \mathrm{KI}$ buffered solution from Droplet Measurement Technology. It is coupled to a meteorological radiosonde M10 from MeteoModem.

The effective vertical resolution of the ozone data is between 50 and $100 \mathrm{~m}$. The ozone measurement accuracy is approximately $4 \%$ in the stratosphere below the $10 \mathrm{hPa}$ pressure level and the precision in total ozone column measured by the sonde is approximately $5 \%$. These ozone measurements are part of the SHADOZ (Southern Hemisphere Additional Ozonesondes) (Thompson et al., 2003) and the NDACC networks.

\subsubsection{WIRA}

WIRA is the first ground-based microwave wind radiometer. It was built at IAP and measures the Doppler shift in the emission spectrum of middle atmospheric ozone at $142 \mathrm{GHz}$ in order to derive middle atmospheric meridional and zonal wind profiles (Rüfenacht et al., 2014). In routine operation, a cycle contains the measurement of signals from two calibration targets as well as from four cardinal directions for the wind retrieval. The retrieval of wind profiles combines the calibrated spectra obtained at two opposite viewing directions (i.e. east and west for zonal and north and south for meridional wind). The prototype of the instrument as well as its operation mode and calibration scheme are described in detail in Rüfenacht et al. (2012). The retrieval method is presented in Rüfenacht et al. (2014). It covers an altitude range from 35 to $75 \mathrm{~km}$, with a vertical resolution between 10 and $16 \mathrm{~km}$.

\subsubsection{ECMWF}

The European Centre for Medium-Range Weather Forecasts (ECMWF) provides global analyses of atmospheric ozone from the ground to the lower mesosphere. Ozone profiles can be obtained using two different products from ECMWF: operational analysis or reanalysis. ERA-Interim (Dee et al., 2011 ) is their latest global atmospheric reanalysis dataset and provides profiles every $6 \mathrm{~h}$, for 60 pressure levels between the surface and $0.1 \mathrm{hPa}$. The altitude range of the operational analysis reaches pressure levels up to $0.01 \mathrm{hPa}$ with a vertical resolution of 137 levels. The time resolution is $6 \mathrm{~h}$ as well. ECMWF models assimilate radiosondes, ground-based atmospheric observations together with modern hyperspectral instruments such as Infrared Atmospheric Sounding Interferometer, Advanced Infrared Sounder, Advanced Microwave Sounding Unit (AMSU) instruments along with GPS radio occultation observations. For the validation of GROMOS-C we compare with the operational data, because our retrieval altitude range goes up to $0.03 \mathrm{hPa}$. 


\section{Results of ozone measurements}

\subsection{Ozone retrievals}

Before the spectra are fed to the inversion process a preprocessing is performed in order to correct the measurement for attenuation arising from the microwave window and tropospheric absorption (see Sect. 3 of Fernandez et al., 2015). Water vapour inhomogeneities in the troposphere are difficult to model and therefore it is important to correct the measured spectra for the tropospheric effect. Tropospheric opacity is calculated from the wings of the measured spectra (NavasGuzmán et al., 2015) and subtracted from it. Afterwards the lower limit for the retrieval is located at the tropopause level. The spectral baseline is removed by allowing the optimal estimation method to fit a polynomial of degree 2 .

For the standard retrieval of GROMOS-C, we use the whole frequency resolution of the spectrometer, and a bandwidth of $300 \mathrm{MHz}$. Reduction of the noise level of the spectra is performed by integration in time, with a minimum time resolution of $1 \mathrm{~h}$. Ozone profiles are retrieved from the resulting averaged spectra, yielding a reliable profile from roughly 23 to $70 \mathrm{~km}$, with a vertical resolution of $10-15 \mathrm{~km}$ depending on the pressure level.

The inversion process requires an a priori knowledge of the vertical ozone profile. This a priori information is taken from a zonal mean climatology using monthly mean Aura MLS data from 2004 to 2013 . The a priori covariance matrix used has a fixed maximum value for the diagonal elements of $0.4 \mathrm{ppm}$ and a Gaussian correlation decay at neighbouring levels. The covariance matrix of the measurement is built as a diagonal matrix, where the elements in the diagonal are the squares of the noise of the spectra, which are assumed constant for all channels. Forward model calculations require a temperature-pressure-altitude profile. These data are taken from the ECMWF model for the corresponding time and location, interpolated to the pressure grid. Spectroscopic parameters for the ozone line are taken from the JPL and HITRAN catalogs. We used the oxygen and water continuum and peaks from the Rosenkranz model (Rosenkranz, 1998). We used water vapour profiles from the ECMWF model and oxygen and nitrogen mixing ratios are assumed to be constant.

An example of a daily mean retrieved ozone profile is shown in Fig. 3a, together with the a priori profile used for the retrieval and the error bars (dashed lines), which represent the total retrieval error, that is, the sum of the observation and smoothing error. The corresponding averaging kernels and measurement response are shown in Fig. 3b. The averaging kernel matrix represents the sensitivity of the retrieved profile to the true atmospheric profile. The area of the kernels, called measurement response, is used as an indicator of the sensitive altitude range of the retrieval. We assume this altitude range delimited by the levels where the measurement response is larger than 0.8 , which corresponds to pressure

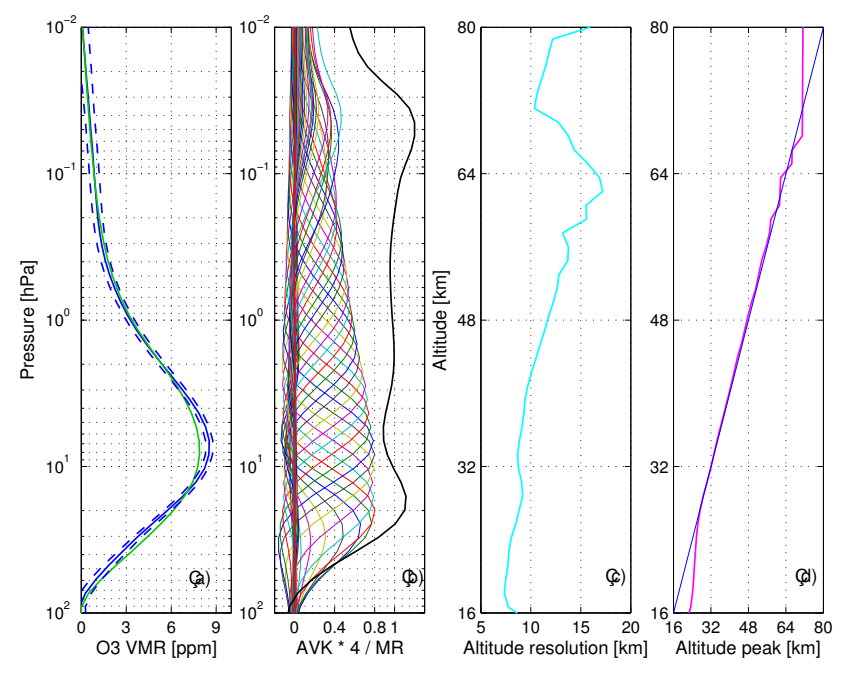

Figure 3. (a) Example of a daily mean retrieved ozone profile (solid blue line) together with the a priori profile used for the inversion (green line) and the total error limits (dashed blue lines). (b) The corresponding averaging kernels multiplied by 4 (colour lines) and the measurement response (black line). (c) Full width at half maximum of the averaging kernels as a measure of vertical resolution. (d) Altitude of the averaging kernels peak.

levels between 30 and $0.02 \mathrm{hPa}(24$ to $75 \mathrm{~km})$. The full width at half maximum of the averaging kernels gives a measure of the vertical resolution. The averaging kernel widths (Fig. 3c) are about $7 \mathrm{~km}$ in the lower stratosphere and increase with altitude up to $17 \mathrm{~km}$ in the middle mesosphere. Figure $3 \mathrm{~d}$ shows the altitude peak of the corresponding kernels maximised at their nominal altitude for the altitude range under consideration.

The operative cycle of GROMOS-C contains the measurement of the sky signal from four directions of view. The spectra of two opposite view directions (east-west and northsouth) are combined in order to retrieve zonal and meridional wind profiles. Ozone retrievals can also be performed individually for each direction, to study possible inhomogeneities of the ozone distribution, which are neglected for the wind retrievals. All sky measurements are performed at an elevation angle of $22^{\circ}$, which implies that two points located at the stratopause level in north and south directions are separated horizontally by a distance of circa $250 \mathrm{~km}$. In stable conditions this constitutes a reasonable range over which to neglect ozone inhomogeneities.

Figure 4 shows four ozone profiles corresponding to the four directions of view of GROMOS-C. Each of them has been calculated taking the mean of the daily mean profiles for the whole campaign period, from mid-June to mid-January. The right plot shows the mean relative difference profile, calculated in percent and with respect to the east. From $60 \mathrm{hPa}$ to roughly $0.02 \mathrm{hPa}$ the differences are within $2 \%$, except for the south, and higher up they appear to increase with altitude. The increases in differences with altitude is consistent with 

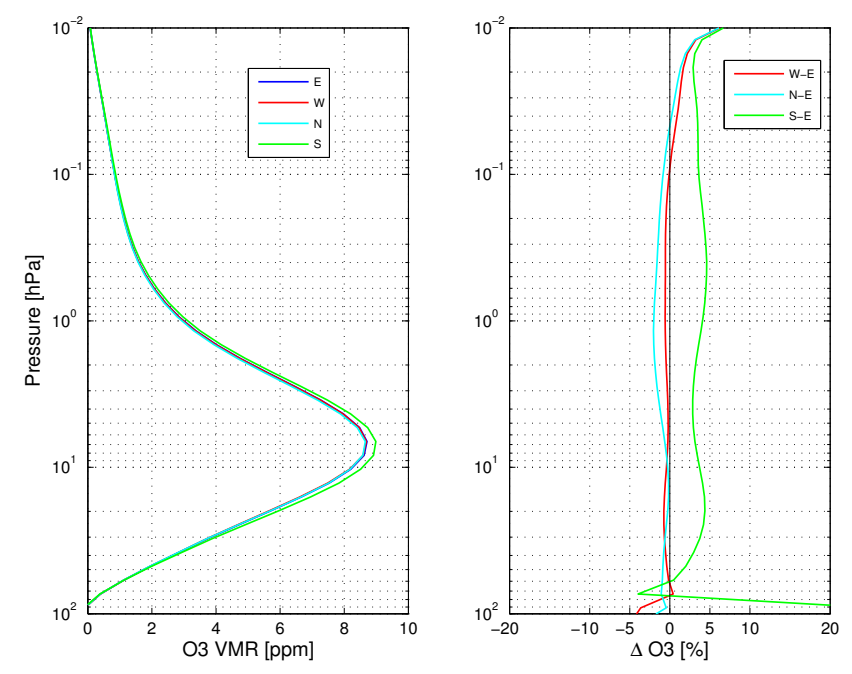

Figure 4. Comparison of ozone profiles in four directions of view. Each profile corresponds to the whole campaign mean of daily mean profiles. The right plot shows the relative differences with respect to the east profile.

an increase in horizontal distance between points in opposite directions. Therefore these discrepancies could be explained as differences in the ozone distribution. A positive bias of nearly $5 \%$ in ozone is notable at all altitudes in measurements toward the south. This bias is a result of an offset in elevation angle present only in the measurements toward the south.

\subsection{Comparing the calibration methods}

As mentioned above, multiple calibration techniques are used to generate GROMOS-C data. We have a blackbody target cooled with Peltier elements to $240 \mathrm{~K}$ used as the default cold load, and a similar load heated with resistors to $350 \mathrm{~K}$ used as default hot load; additionally we have a noise diode used as super-hot load adding circa $300 \mathrm{~K}$, and tipping curves are performed regularly in order to use the zenith sky as an alternative cold load. In Fernandez et al. (2015) spectra calibrated with different methods were compared. In this section, we compare the influence of these calibration methods on the retrievals.

Figure 5 displays the spectrum and retrieved profile for a day at the beginning of the campaign, the 23 June, for the three different calibration methods. A tropospheric correction has been applied to all spectra, so the retrieval starts at the tropopause level. Both the noise diode and hot-Peltier spectra have similar noise levels, which results in similar retrievals. However, the spectrum calibrated with the tipping curve exhibits a higher noise level, therefore the retrieval takes more information from the a priori. That could be the reason why this retrieved profile is closer to the reference MLS profile (in red), since we use MLS climatology as a priori profile. The upper limit of the measurement response is also lower, $0.035 \mathrm{hPa}$, compared to $0.02 \mathrm{hPa}$ in the other cases. This corresponds to a larger uncertainty in the profile from that level. Besides, the altitude resolution is degraded. The higher noise level in the tipping curve calibration is likely a result of zenith sky measurements, which are not long enough. A zenith measurement is taken only every $15 \mathrm{~min}$. Therefore, the cold sky integration time is relatively short and the noise in this measurement is larger than the noise in the $22^{\circ}$ measurement. This problem could likely be eliminated by raising the frequency of the tippings or increasing the integration time for the retrievals.

We started the campaign in winter (June) with good atmospheric conditions, i.e., low humidity, frequent clear skies and, therefore, low optical thickness (Fig. 2). However, towards the summer the temperature and humidity increased leading to higher opacity. Under these conditions, a baseline emerged on the calibrated ozone spectra. We found that its origin was at the Peltier load and we believe it could be due to the condensation of water on the window of the load if the dew point was reached. As water is not transparent to microwave radiation, part of the radiation would be backscattered and a standing wave would be created between the load and the antenna, which added a baseline to the spectra. Performing inversions of spectra with such a ripple would have considerable impact on the retrieval. Therefore, in such conditions we prefer other methods of calibration.

It is important to point out that the baseline effect can be circumvented by the use of other calibration techniques and this ability to alternate calibration methods is an important advantage of the measurement approach.

\subsection{Validation of the ozone time series}

In this section we validate GROMOS-C retrieved profiles against other ozone profiles measured with different techniques. We have used tipping curve calibrated spectra for the daily mean comparison, but for shorter integration time we have considered the noise diode calibration because the altitude range where the measurement response is larger than 0.8 goes up to higher layers, allowing for a fair comparison also in the mesosphere.

The time series of ozone profiles measured by GROMOS$\mathrm{C}$ during the Maïdo campaign are shown in Fig. 6 (top panel). They correspond to retrieved profiles run with an integration time of $2 \mathrm{~h}$, calibrated with the noise diode, for the east direction. Ozone concentration is expressed as volume mixing ratio, in parts per million volume ( $\mathrm{ppm}$ ). The data gap in September corresponds to a week where we shifted the frequency range to measure carbon monoxide instead of ozone, and the gap in December corresponds to a very high opacity period when the inversions did not work. The white lines represent the limits where the measurement response is larger than 0.8 , identifying the altitude range where profiles can be reliable. In most cases these limits range from 30 to $0.03 \mathrm{hPa}$. Before a spectrum is fed to the retrieval, it has to pass a noise 

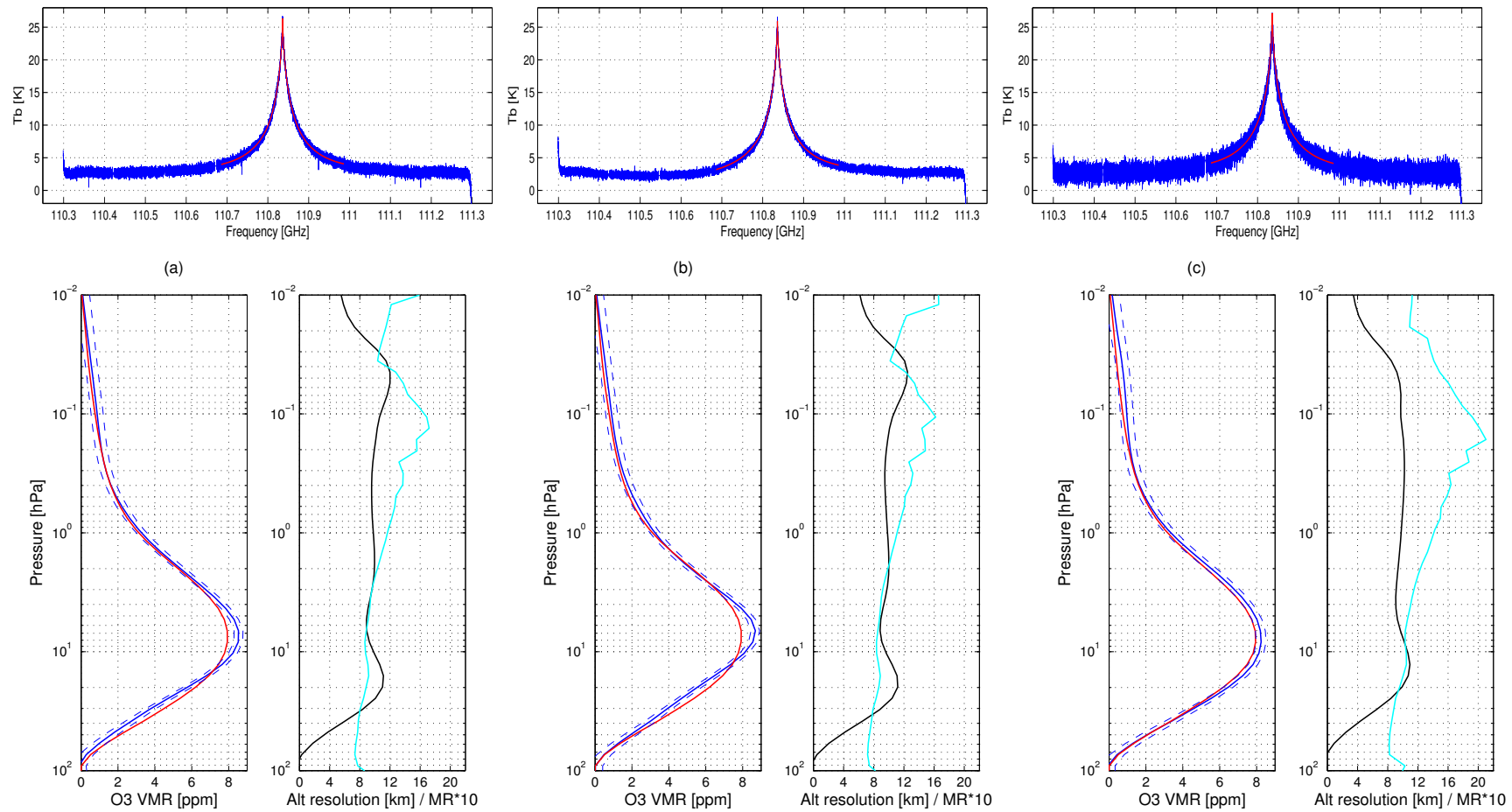

Figure 5. Top: daily mean measured (blue) and simulated (red) ozone spectrum, calibrated with (a) hot and Peltier loads; (b) noise diode and (c) tipping curve. Bottom: corresponding retrieved profiles (solid blue) together with the total error limits (dashed blue lines) and the MLS profile (red), measurement response multiplied by 10 (black) and altitude resolution (cyan).

level test and be taken within certain limits of opacity and system temperature. If a spectrum fails any of these tests, it is discarded. In that case, the considered integration time will present a higher noise, affecting the averaging kernels of the inversion and decreasing the boundaries for the reliable profiles. We observed a decreased altitude range for the last month of data, which corresponds to the very humid period with high opacity.

A comparable plot of Aura MLS ozone profiles is shown in Fig. 6 (bottom). The similarity is striking. The annual cycle increase in ozone in the middle stratosphere from winter to summer due to increased solar radiation is obvious. The diurnal cycle is also perceptible. Special features of this dataset are discussed in Sect. 6.

For a more quantitative comparison we have divided the profiles into three pressure levels, and plotted the mean volume mixing ratio for each layer (Fig. 7). Each point corresponds to a daily mean value; this time we have opted for the tipping curve calibration for the comparison. We chose altitude levels at $25-10,10-2$ and $2-0.5 \mathrm{hPa}$, which correspond roughly to the lower, middle and upper stratosphere. We compared our measurements to those from MLS, lidar, radiosondes and with the model data from ECMWF. The radiosonde comparison is only available for the first layer because the balloons normally burst at circa $30 \mathrm{~km}$. The lidar is not available for the highest layer under comparison. ECMWF and MLS are comparable at all levels.
On the right plot we display the relative differences with respect to GROMOS-C. Until mid-December, all measurements are within $10 \%$. After mid-December, large fluctuations due to high opacity are problematic for GROMOS$\mathrm{C}$ measurements. We cannot explain an apparent bias in ECMWF model results in the middle and upper stratosphere with respect to the measurements of MLS, GROMOS-C and lidar.

A more detailed comparison is shown in Fig. 8, where we plot a single GROMOS-C daily mean profile together with the equivalent profiles obtained from MLS, ECMWF, lidar and radiosonde. All of the profiles present a higher vertical resolution than GROMOS-C retrievals. We therefore have to convolve each of them with the averaging kernels of our inversions according to the following:

$x_{\text {conv }}=A \cdot\left(x-x_{\mathrm{a}}\right)+x_{\mathrm{a}}$,

where $A$ is the averaging kernels matrix, $x$ stands for the $\mathrm{O}_{3}$ profile and $x_{\mathrm{a}}$ is the a priori profile of our retrievals. The convolution decreases the vertical resolution of the measured profiles and allows for an adequate comparison.

Figure 8 includes both the original unconvolved profiles plus the convolved ones. The relative differences between the convolved profiles relative to GROMOS-C is clear in the right plot in Fig. 8. Results show agreement with the satellite profile within $5 \%$ up to $0.2 \mathrm{hPa}$ and within $10 \%$ for the ECMWF profile. The agreement with lidar data is within 

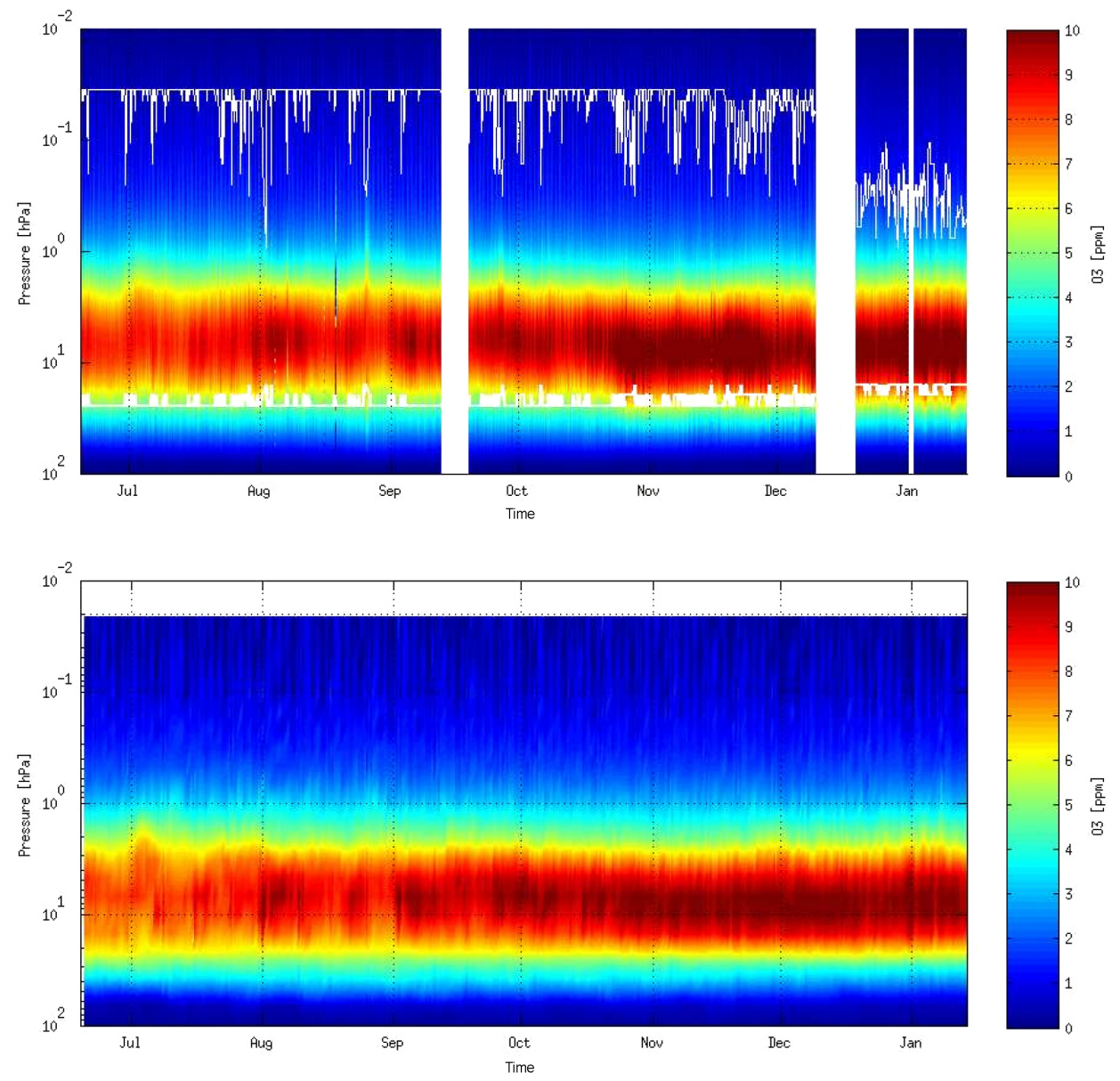

Figure 6. Time series of ozone profiles measured by GROMOS-C during the Maïdo campaign (top); the white lines represent the limits where the measurement response is larger than 0.8. Equivalent plot with Aura-MLS ozone profiles (bottom).

$5 \%$, but the comparison to the radiosonde data shows more discrepancies, especially at lower altitude levels. However, keep in mind, GROMOS-C data reliability range starts at an altitude of $30 \mathrm{hPa}$. The bias decreases from 13 to $4 \%$ with increasing altitude. Above $0.1 \mathrm{hPa}$, the GROMOS-C retrieval appears to overestimate the volume mixing ratio of ozone. In the mesosphere the ozone concentration becomes so low a small discrepancy affects the relative difference in a significant way.

\section{Result of wind measurements}

Although GROMOS-C was primarily designed for observations of ozone and carbon monoxide profiles its setup includes the capacity for middle-atmospheric wind measurements. Thanks to its relatively low noise temperature, its sufficient spectral resolution and to its ability to observe the atmosphere in the four cardinal directions, zonal and meridional wind profiles can be assessed. The wind profiles are determined from the Doppler shifts of different parts of the pressure-broadened ozone emission spectrum, as first described by Rüfenacht et al. (2014), through an optimal estimation inversion. The retrieval is performed with the ARTS/QPACK software package (Eriksson et al., 2011, 2005). A constant zero wind a priori profile is considered, together with a relatively large variance. The atmospheric parameters of the forward and inverse model for the GROMOS$\mathrm{C}$ wind retrieval were set analogously to the ones of the retrieval for the wind radiometer WIRA (see Sect. 4 of Rüfenacht et al., 2014), taking into account that GROMOS$\mathrm{C}$ measures the $110 \mathrm{GHz}$ ozone emission line rather than $142 \mathrm{GHz}$.

The time series of GROMOS-C daily average wind profiles for a test phase of 6 months are shown in Fig. 9. For comparison, measurements by the co-located wind radiometer (WIRA) and ECMWF model data are also shown. The grey lines in the upper panels represent the upper and lower limit of the trustworthy altitude range. This range is defined to be the region where the measurement response is higher than 0.8 , the altitude resolution better than $20 \mathrm{~km}$, and the altitude accuracy (defined as the offset between the peak al- 

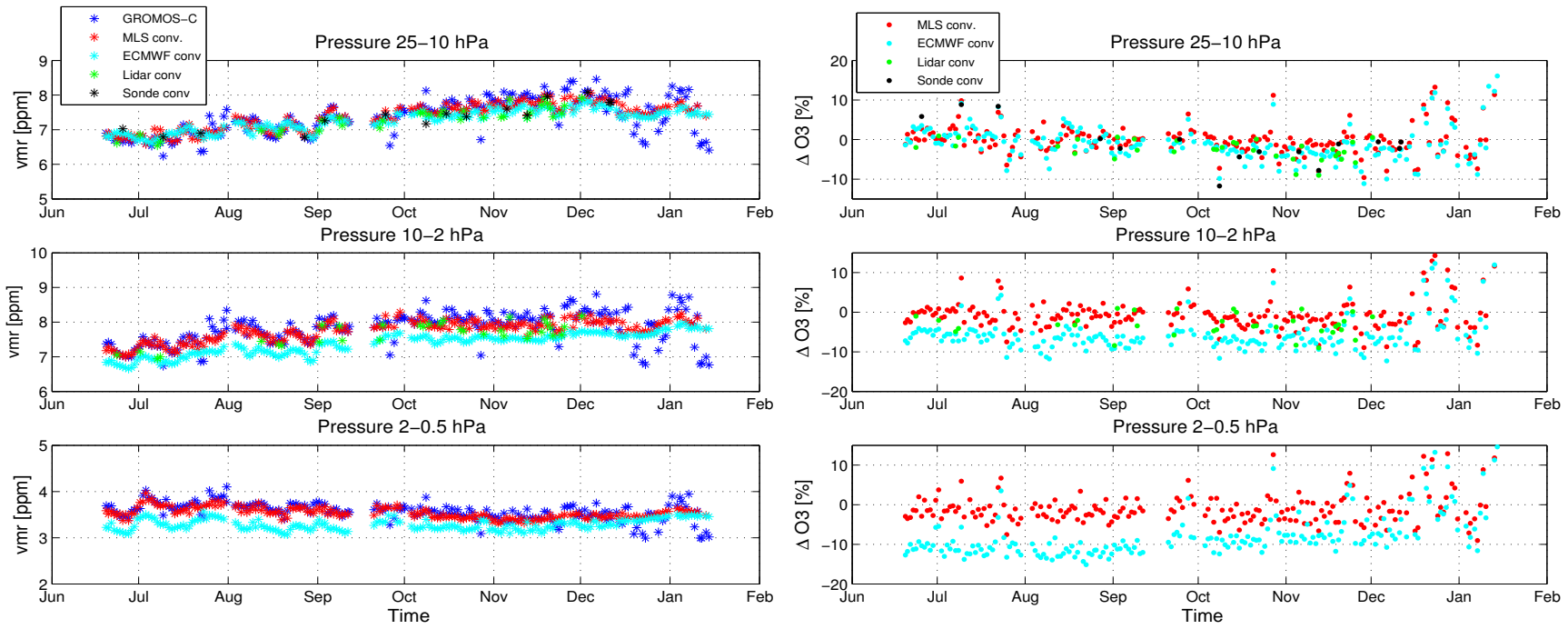

Figure 7. Daily mean time series of ozone volume mixing ratio measured by GROMOS-C and compared to MLS, ECMWF, lidar and radiosonde ozone measurements, for three pressure intervals (left). The plotted vmr (volume mixing ratio) are averages over the indicated pressure intervals. Corresponding relative differences (right), calculated according to $\Delta \mathrm{O}_{3}=\left(\mathrm{O}_{3 \text { (compared) }}-\mathrm{O}_{3 \text { (gromos-c) }}\right) / \mathrm{O}_{3 \text { (gromos-c) }}$. 100
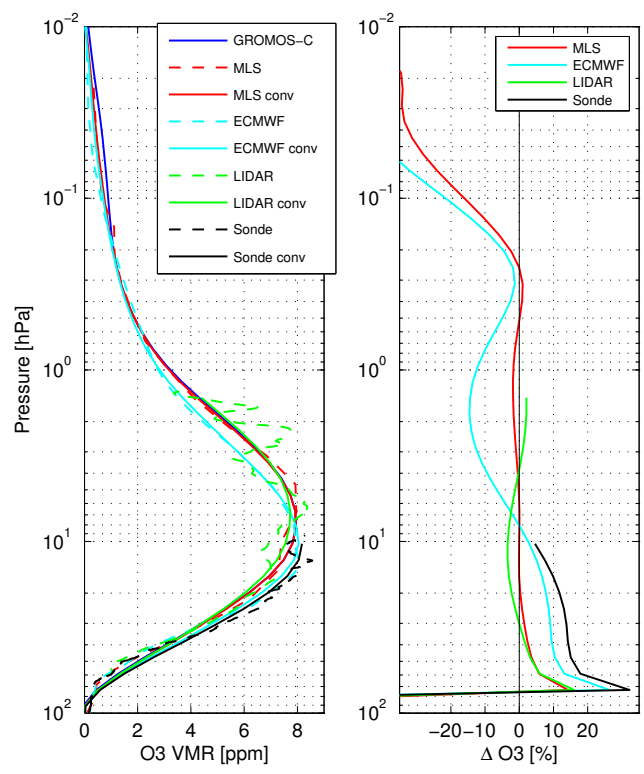

Figure 8. Comparison of a daily mean GROMOS-C ozone profile with MLS, ECMWF, lidar and radiosonde. We have included both the original and the convolved profiles. The right plot shows the relative differences of the convolved profiles with respect to GROMOS-C, $\Delta \mathrm{O}_{3}=\left(\mathrm{O}_{3 \text { (compared) }}-\mathrm{O}_{3 \text { (gromos-c) })}\right) / \mathrm{O}_{3 \text { (gromos-c) }}$. 100 .

titude and the nominal altitude of the averaging kernel) is better than $4 \mathrm{~km}$. In the vast majority of cases, the trustable altitude range for GROMOS-C is delimited by the averaging kernel criterion. Data outside the trustable altitude range should not be considered.
The overall agreement between GROMOS-C, WIRA and ECMWF is clearly visible. The principal features such as the stratospheric wind reversal in July 2014 are captured by GROMOS-C. Due to the design and operation mode, which is not optimized for wind measurements, the uncertainties of the GROMOS-C observations are larger and the altitude range is smaller than those of WIRA. Nevertheless, this comparison indicates the potential of GROMOS-C to perform zonal wind measurements over the altitude range of 40 to $60 \mathrm{~km}$.

A more quantitative comparison between GROMOS-C, WIRA, and ECMWF is given in Fig. 10 which displays the average differences in zonal wind throughout the 6-month period of wind retrievals. The ECMWF profiles were convolved with the averaging kernels of GROMOS-C according to Eq. (1) so that the limited vertical resolution of the GROMOS-C wind retrieval does not influence the comparison. The profiles by WIRA have a similar altitude resolution and thus do not need to be convolved to obtain meaningful interpretations of the differences. GROMOS-C's wind profiles are in good agreement with the observations by the wind radiometer WIRA and with the model data from ECMWF, differences are below $5 \mathrm{~m} \mathrm{~s}^{-1}$ for both. The slight negative bias of GROMOS-C with respect to ECMWF and WIRA is mostly not significant and might be interpreted as a random feature.

\section{Special case study}

Figure 6 shows an increase of ozone in early July between 4 and $1 \mathrm{hPa}$. This increase is evident in data from both 

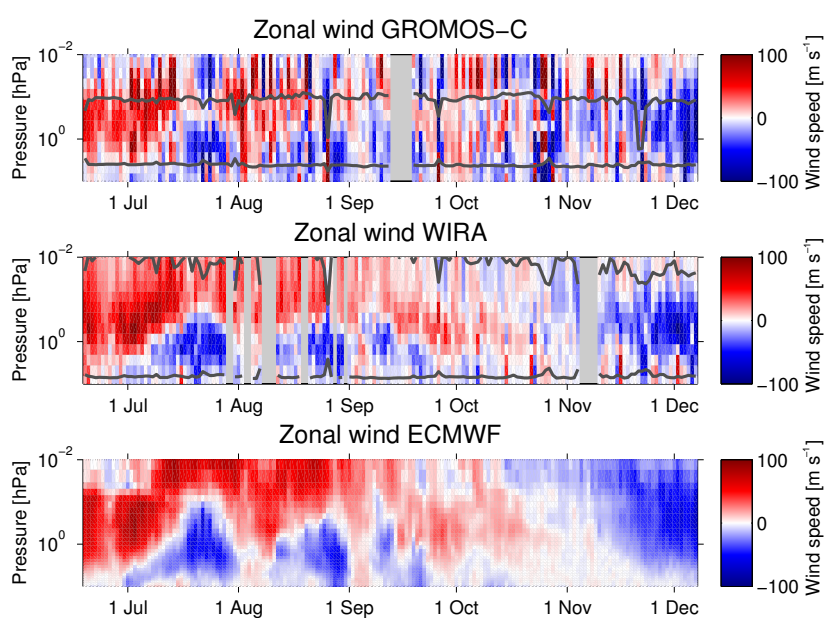

Figure 9. Middle-atmospheric zonal wind profiles measured by the radiometers GROMOS-C and WIRA as well as model data from ECMWF. The grey horizontal lines delimit the trustable altitude range which is basically equivalent to a measurement response larger than 0.8 for GROMOS-C.

GROMOS-C and MLS. This feature is presented in more detail in Fig. 11. The time series of ozone profiles measured by GROMOS-C have been plotted together with the isentropes (lines of equal potential temperature) taken from the ECMWF model. As air parcels travel on surfaces of equal potential temperature, the isentropes can be used to study the airflow and to identify vertical displacements. In Fig. 11, an updraft is identified by dashed lines and by deviations of the isentropes at 1200,1400 , and $1600 \mathrm{~K}$. The updrafted airmass has higher ozone mixing ratios and results in higher ozone at the corresponding pressure levels.

The time series of temperature profiles from the ECMWF model are shown in the middle plot. A substantial decrease of temperature is observed within the same time period mainly at pressure levels between 4 and $1 \mathrm{hPa}$, which is also explained by the updraft of air from colder layers. During this event strong zonal winds of up to $90 \mathrm{~km} \mathrm{~h}^{-1}$ are observed in the ECMWF model (Fig. 11, bottom) followed by an intense east to west wind reversal.

\section{Conclusions}

The first validation campaign of GROMOS-C took place at the Maïdo observatory on Réunion island, from June 2014 to January 2015 . We validated the GROMOS-C capability to measure continuous ozone profiles with high temporal resolution for a broad altitude range.

We have confirmed that different calibration methods lead to equivalent retrieved profiles as long as the spectra are baseline free. We demonstrated the advantages of using multiple calibration methods. When the Peltier load method failed due to high humidity, we had the option to use a different ap-

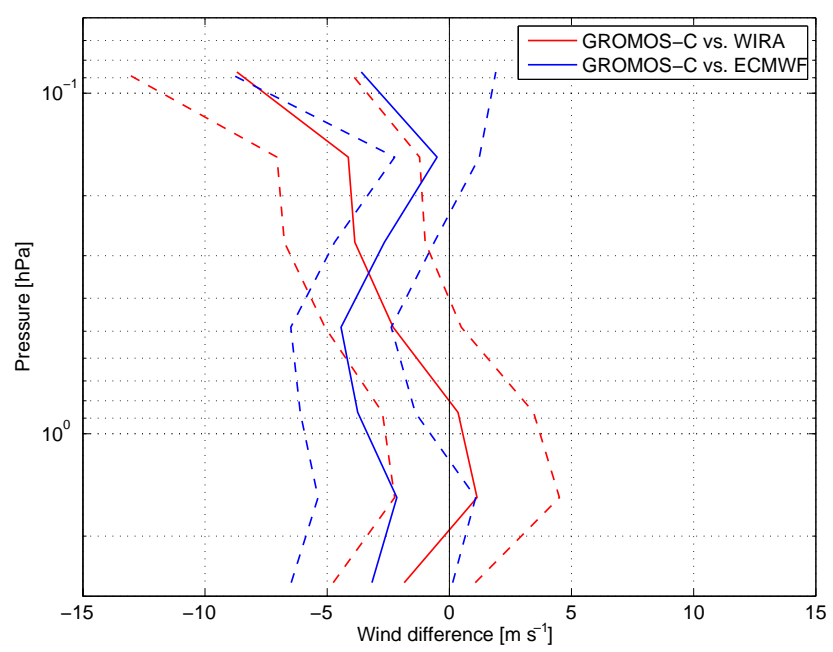

Figure 10. Differences of zonal wind profiles between GROMOS-C and WIRA ( $\left.u_{\text {GROMOS-C }}-u_{\text {WIRA }}\right)$ as well as between GROMOS$\mathrm{C}$ and ECMWF ( $\left.u_{\mathrm{GROMOS}-\mathrm{C}}-u_{\mathrm{ECMWF}}\right)$. The solid lines represent the average differences for the time period shown in Fig. 9 whereas the dashed lines mark the errors of the average profile, i.e. the standard deviation of the differences divided by the square root of the number of contributing measurements. Only altitudes with more than 15 days of trustworthy data have been considered in the analysis.

proach. The tipping curve method works well at very low brightness temperatures. It is easy to implement. However, the calculation is time consuming and less accurate for cloud conditions. Further, the tipping curve method produces noisier spectra because the integration time for the cold sky measurements was short. This approach should be used when longer integration times are possible. The noise diode approach needs recalibration if the system temperature fluctuates. This approach should be used when the system is thermally stable. The Peltier and hot loads are thermally stabilised and not weather dependent. They constitute the default calibration technique of GROMOS-C. During this campaign, when temperatures dropped below the dew point, water condensed on a window interfering with the measurement. This problem was fixed after the campaign by displacing moist air with dry nitrogen.

The measurement response of the retrievals of GROMOS$\mathrm{C}$ is larger than $80 \%$ for pressure levels between 30 and $0.02 \mathrm{hPa}$ (24 to $75 \mathrm{~km})$. The vertical resolution goes from $7 \mathrm{~km}$ in the lower stratosphere, increasing with altitude up to $17 \mathrm{~km}$ in the middle mesosphere. The averaging kernels peak at its nominal altitude over this altitude range.

Validation has been performed using ozone profiles from Aura MLS satellite, the ozone lidar located in the observatory and with ozone profiles from weekly radiosondes, as well as with data from the ECMWF model. Results show an agreement with MLS profiles within $5 \%$ up to $0.2 \mathrm{hPa}$ and within $10 \%$ for the ECMWF profile. Agreement with the lidar is 

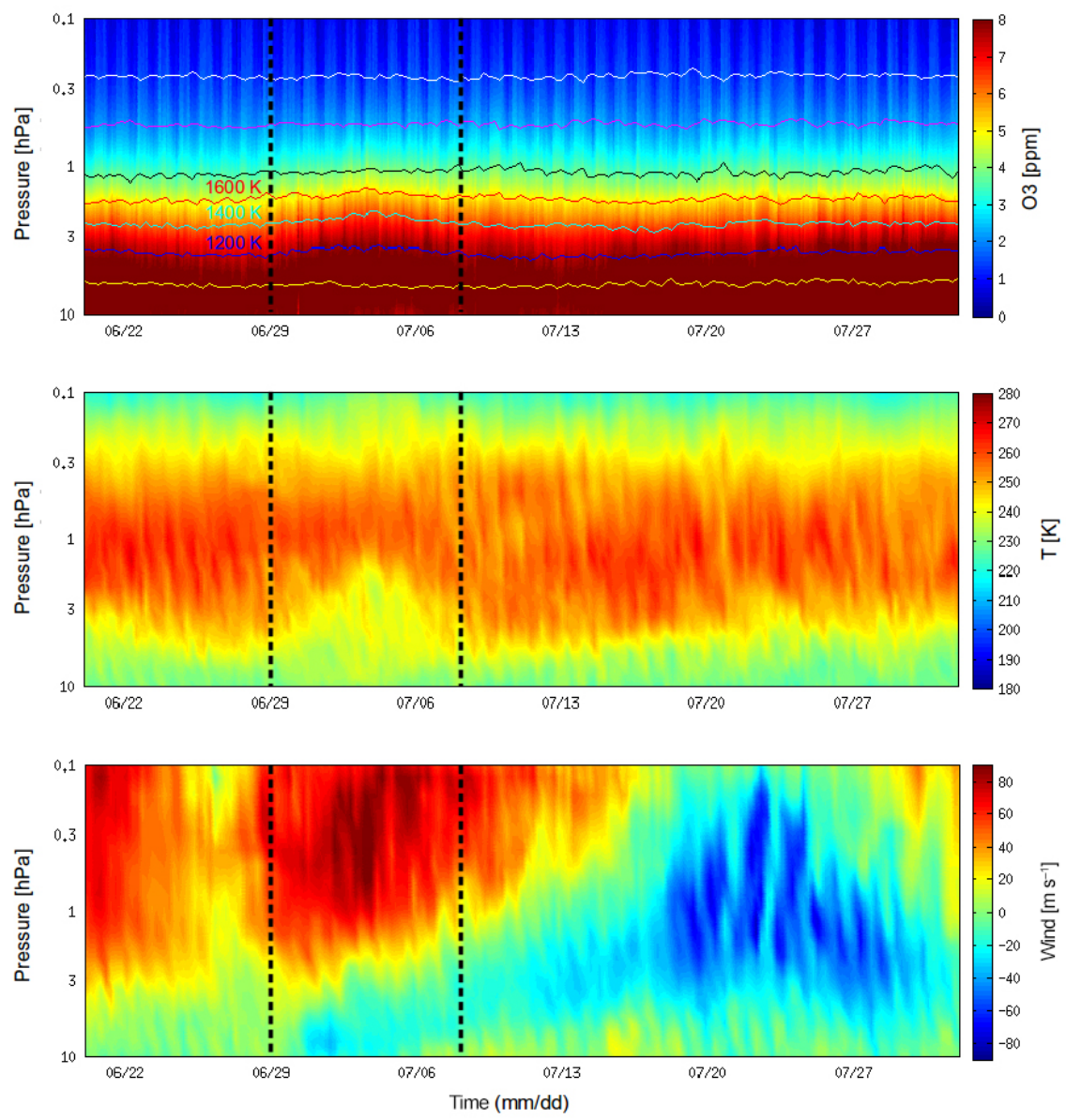

Figure 11. Zoom in the time series of ozone profiles measured by GROMOS-C plotted together with the isentropes from ECMWF (top), temperature profiles from ECMWF (middle) and zonal wind profiles from ECMWF (bottom). The black dashed lines delimit the time period when the air updraft happened.

within $5 \%$ at all levels of comparison. Radiosonde data show more discrepancies especially at lower altitudes.

Although GROMOS-C was mainly designed for ozone observations its setup allows for middle-atmospheric wind profile measurements. The four directions of view allow retrieval of zonal and meridional winds from the Doppler shift. Winds measured by GROMOS-C have been compared with data from another co-located wind radiometer (WIRA) and with output from the ECMWF model. The retrieved wind profiles are in good agreement with the observations by WIRA and with the model data, with differences below $5 \mathrm{~m} \mathrm{~s}^{-1}$ for both. Important meteorological features such as the stratospheric wind reversal in July are clearly evident in GROMOS-C data. Thus GROMOS-C measurements can also be used to retrieve middle atmospheric wind profiles.

We also identified an updraft event from an increase of ozone measured by GROMOS-C.

The high temporal resolution ozone dataset presented here is unique for this location and will be useful given the dearth of such data from tropical locations. In a future study it would be interesting to investigate the ozone diurnal cycle which has not been studied for such a tropical location.

\section{Data availability}

The data are available upon request (contact email: susana.fernandez@iap.unibe.ch).

Acknowledgements. This work has been funded by the Swiss National Science Foundation under grant number 200020-160048. The authors want to thank the electronics workshop of the IAP for their support during the campaign. The authors acknowledge the European Communities, the Région Réunion, CNRS, and Université de la Réunion for their support and contribution in the construction phase of the research infrastructure OPAR (Observatoire de Physique de l'Atmosphère à La Réunion). OPAR is presently funded by CNRS (INSU) and Université de La Réunion, and managed by OSU-R (Observatoire des Sciences de l'Univers à La Réunion, UMS 3365).

Edited by: H. Maring 


\section{References}

Baray, J.-L., Courcoux, Y., Keckhut, P., Portafaix, T., Tulet, P., Cammas, J.-P., Hauchecorne, A., Godin Beekmann, S., De Mazière, M., Hermans, C., Desmet, F., Sellegri, K., Colomb, A., Ramonet, M., Sciare, J., Vuillemin, C., Hoareau, C., Dionisi, D., Duflot, V., Vérèmes, H., Porteneuve, J., Gabarrot, F., Gaudo, T., Metzger, J.-M., Payen, G., Leclair de Bellevue, J., Barthe, C., Posny, F., Ricaud, P., Abchiche, A., and Delmas, R.: Maïdo observatory: a new high-altitude station facility at Reunion Island $\left(21^{\circ} \mathrm{S}, 55^{\circ} \mathrm{E}\right)$ for long-term atmospheric remote sensing and in situ measurements, Atmos. Meas. Tech., 6, 2865-2877, doi:10.5194/amt-62865-2013, 2013.

Brasseur, G. P. and Solomon, S.: Aeronomy of the Middle Atmosphere, Springer, Dordrecht, the Netherlands, 2005.

Butchart, N., Scaife, A., Bourqui, M., De Grandpré, J., Hare, S., Kettleborough, J., Langematz, U., Manzini, E., Sassi, F., Shibata, K., et al.: Simulations of anthropogenic change in the strength of the Brewer-Dobson circulation, Clim. Dynam., 27, 727-741, 2006.

Dee, D., Uppala, S., Simmons, A., Berrisford, P., Poli, P., Kobayashi, S., Andrae, U., Balmaseda, M., Balsamo, G., Bauer, P., Bechtold, P., Beljaars, A., Van den Berg, L., Bidlot, J., Bormann, N., Delsol, C., Dragani, R., Fuentes M., Geer, A., Haimberger, L., Healy, S., Hersbach, H., Holm, E., Isaksen, L., Kallberg, P., Köhle, M., Matricardi, M., McNally, A., Monge-Sanz, B., Morcrette, J., Park, B., Peubey, C., Rosnay, P., Tavolato, C., Thépaut, J., Vitart, F.: The ERA-Interim reanalysis: Configuration and performance of the data assimilation system, Q. J. Roy. Meteor. Soc., 137, 553-597, 2011.

Eriksson, P., Jiménez, C., and Buehler, S. A.: Qpack, a general tool for instrument simulation and retrieval work, J. Quant. Spectrosc. Ra., 91, 47-64, 2005.

Eriksson, P., Buehler, S., Davis, C., Emde, C., and Lemke, O.: ARTS, the atmospheric radiative transfer simulator, version 2, J. Quant. Spectrosc. Ra., 112, 1551-1558, 2011.

Fernandez, S., Murk, A., and Kämpfer, N.: GROMOS-C, a novel ground-based microwave radiometer for ozone measurement campaigns, Atmos. Meas. Tech., 8, 2649-2662, doi:10.5194/amt-8-2649-2015, 2015.

Flury, T., Hocke, K., Haefele, A., Kämpfer, N., and Lehmann, R.: Ozone depletion, water vapor increase, and PSC generation at midlatitudes by the 2008 major stratospheric warming, J. Geophys. Res.-Atmos., 114, D18302, doi:10.1029/2009JD011940, 2009.

Froidevaux, L., Jiang, Y. B., Lambert, A., Livesey, N. J., Read, W. G., Waters, J. W., Browell, E. V., Hair, J. W., Avery, M. A., McGee, T. J., Twigg, L. W., Sumnicht, G. K., Jucks, K. W., Margitan, J. J., Sen, B., Stachnik, R. A., Toon, G. C., Bernath, P. F., Boone, C. D., Walker, K. A., Filipiak, M. J., Harwood, R. S., Fuller, R. A., Manney, G. L., Schwartz, M. J., Daffer, W. H., Drouin, B. J., Cofield, R. E., Cuddy, D. T., Jarnot, R. F., Knosp, B. W., Perun, V. S., Snyder, W. V., Stek, P. C., Thurstans, R. P., and Wagner, P. A.: Validation of Aura Microwave Limb Sounder stratospheric and mesospheric ozone measurements, J. Geophys. Res.-Atmos., 113, D15S20, doi:10.1029/2007JD008771, 2008.

Godin-Beekmann, S., Porteneuve, J., and Garnier, A.: Systematic DIAL lidar monitoring of the stratospheric ozone vertical distribution at Observatoire de Haute-Provence $\left(43.92^{\circ} \mathrm{N}, 5.71^{\circ} \mathrm{E}\right), \mathrm{J}$. Environ. Monitor., 5, 57-67, 2003.
Navas-Guzmán, F., Kämpfer, N., Murk, A., Larsson, R., Buehler, S. A., and Eriksson, P.: Zeeman effect in atmospheric $\mathrm{O}_{2}$ measured by ground-based microwave radiometry, Atmos. Meas. Tech., 8 , 1863-1874, doi:10.5194/amt-8-1863-2015, 2015.

Parrish, A., Boyd, I. S., Nedoluha, G. E., Bhartia, P. K., Frith, S. M., Kramarova, N. A., Connor, B. J., Bodeker, G. E., Froidevaux, L., Shiotani, M., and Sakazaki, T.: Diurnal variations of stratospheric ozone measured by ground-based microwave remote sensing at the Mauna Loa NDACC site: measurement validation and GEOSCCM model comparison, Atmos. Chem. Phys., 14, 7255-7272, doi:10.5194/acp-14-7255-2014, 2014.

Randel, W. J. and Thompson, A. M.: Interannual variability and trends in tropical ozone derived from SAGE II satellite data and SHADOZ ozonesondes, J. Geophys. Res.-Atmos., 116, D07303, doi:10.1029/2010JD015195, 2011.

Rodgers, C. D.: Retrieval of atmospheric temperature and composition from remote measurements of thermal radiation, Rev. Geophys., 14, 609-624, 1976.

Rosenkranz, P. W.: Water vapor microwave continuum absorption: A comparison of measurements and models, Radio Sci., 33, 919928, 1998.

Rüfenacht, R., Kämpfer, N., and Murk, A.: First middleatmospheric zonal wind profile measurements with a new ground-based microwave Doppler-spectro-radiometer, Atmos. Meas. Tech., 5, 2647-2659, doi:10.5194/amt-5-2647-2012, 2012.

Rüfenacht, R., Murk, A., Kämpfer, N., Eriksson, P., and Buehler, S. A.: Middle-atmospheric zonal and meridional wind profiles from polar, tropical and midlatitudes with the ground-based microwave Doppler wind radiometer WIRA, Atmos. Meas. Tech., 7, 4491-4505, doi:10.5194/amt-7-4491-2014, 2014.

Scheiben, D., Straub, C., Hocke, K., Forkman, P., and Kämpfer, N.: Observations of middle atmospheric $\mathrm{H}_{2} \mathrm{O}$ and $\mathrm{O}_{3}$ during the 2010 major sudden stratospheric warming by a network of microwave radiometers, Atmos. Chem. Phys., 12, 7753-7765, doi:10.5194/acp-12-7753-2012, 2012.

Straub, C., Murk, A., and Kämpfer, N.: MIAWARA-C, a new ground based water vapor radiometer for measurement campaigns, Atmos. Meas. Tech., 3, 1271-1285, doi:10.5194/amt-31271-2010, 2010.

Stübi, R., Levrat, G., Hoegger, B., Viatte, P., Staehelin, J., and Schmidlin, F.: In-flight comparison of Brewer-Mast and electrochemical concentration cell ozonesondes, J. Geophys. Res.Atmos., 113, D13302, doi:10.1029/2007JD009091, 2008.

Studer, S., Hocke, K., Schanz, A., Schmidt, H., and Kämpfer, N.: A climatology of the diurnal variations in stratospheric and mesospheric ozone over Bern, Switzerland, Atmos. Chem. Phys., 14, 5905-5919, doi:10.5194/acp-14-5905-2014, 2014.

Thompson, A. M., Witte, J. C., McPeters, R. D., Oltmans, S. J., Schmidlin, F. J., Logan, J. A., Fujiwara, M., Kirchhoff, V. W., Posny, F., Coetzee, G. J., Hoegger, B., Kawakami, S., Ogawa, T., Johnson, B., Vömel, H., and Labow, G.: Southern Hemisphere Additional Ozonesondes (SHADOZ) 1998-2000 tropical ozone climatology 1. Comparison with Total Ozone Mapping Spectrometer (TOMS) and ground-based measurements, J. Geophys. Res.-Atmos., 108, 8238, doi:10.1029/2001JD000967, 2003.

Waters, J. W., Froidevaux, L., Harwood, R. S., Jarnot, R. F., Pickett, H. M., Read, W. G., Siegel, P. H., Cofield, R. E., Filipiak, M. J., Flower, D., Holden, J. R., G. K. Lau, Livesey, N. J., Manney, 
G. L., Pumphrey, H. C., Santee, M. L., Wu, D. L., Cuddy, D. T., Lay, R. R., Loo, M. S., Perun, V. S., Schwartz, M. J., Stek, P. C., Thurstans, R. P., Boyles, M. A., Chandra, K. M., Chavez, M. C., Gun-Shing Chen, Chudasama,B. V., Dodge, R., Fuller, R. A., Girard, M. A., Jiang, J. H., Yibo Jiang, Knosp, B. W., LaBelle, R. C., Lam, J. C., Lee, K. A., Miller, D., Oswald, J. E. , Patel, N. C., Pukala, D., Quintero, O., Scaff, D. M., Van Snyder, W., Tope, M. C. , Wagner, P. A., and Walch, M. J.: The earth observing system microwave limb sounder (EOS MLS) on the Aura satellite, IEEE T. Geosci. Remote Sens., 44, 1075-1092, 2006. 